\title{
Coensino e Educação Física escolar: intervenções voltadas à inclusão de estudantes com deficiência
}

\author{
Co-teaching and School Physical Education: interventions aimedat the \\ inclusion of students with disabilities
}

\section{Co-enseñanza y Educación Física Escolar: intervenciones orientadas a lainclusión de estudiantes con discapacidad}

\author{
Melina Radaelli Gatti \\ Doutoranda na Universidade Federal de São Carlos, São Carlos, SP, Brasil \\ E-mail: melinaradaelli@hotmail.com ORCID: https://orcid.org/0000-0003-3379-8138
}

Mey de Abreu van Munster

Professora pós-doutora da Universidade Federal de São Carlos, São Carlos, SP, Brasil

E-mail: munster.mey@gmail.com ORCID: https://orcid.org/0000-0003-2943-5967

Recebido em 26 de maio de 2021

Aprovado em 24 de outubro de 2021

Publicado em 18 de novembro de 2021

\section{RESUMO}

Sob a perspectiva da educação inclusiva, a Educação Física Escolar (EFE) tem procurado assegurar oportunidades de participação efetiva aos estudantes com deficiência (ECD). Todavia, o professor de Educação Física (PEF) ainda encontra muitos desafios, entre os quais se destaca a falta de serviços de apoio à inclusão em sua área. Surge então o interesse em investigar o coensino como possibilidade de apoio ao PEF. Assim, o objetivo deste trabalho centra-se em descrever e analisar intervenções, por meio da aplicação do coensino pelos agentes protagonistas (PEF, ECD e seus pares), enquanto apoio para promover a inclusão de ECD no contexto da EFE, sob a perspectiva colaborativa. Trata-se de um estudo qualitativo, caracterizado como pesquisa colaborativa. A coleta de dados foi realizada em duas escolas do interior paulista. Os participantes foram três PEF, suas respectivas turmas e um professor colaborador especialista em EFE. Como instrumentos de coleta de dados, foram utilizadas entrevistas semiestruturadas e observação sistemática. $O$ tratamento dos dados foi baseado em análise temática e os resultados foram apresentados em casos, conforme as categorias: a) comunicação; b) coplanejamento; c) distribuição compartilhada de instrução e avaliação; d) resolução de conflito. No caso 1 e 2, foram positivos a intervenção, no caso 3 não, por dificuldades no coplanejamento. Conclui-se que a aplicação do coensino nas aulas de Educação Física é possível e viável, considerando que esta estratégia colaborativa supriu, de maneira específica, as necessidades dos PEF e ECD em dois casos, favorecendo a inclusão no contexto estudado.

Palavras-chave: Educação Física Escolar; Educação Especial; Educação Inclusiva; Ensino Colaborativo; Pessoas com deficiência. 
http://dx.doi.org/10.5902/1984686X65968

\section{ABSTRACT}

From the perspective of inclusive education, School Physical Education (SPE) aims at ensuring opportunities for effective participation of students with disabilities (SWD). However, the Physical Education teacher (PET) still faces many challenges, including the lack of services to support inclusion in his area. Therefore, there is na interest in investigating co-teaching as a possibility of supporting the PET. The objective of this work is describe and analyze an intervention that applied co-teaching by the protagonist agents (PET, SWD and their peers) as support activity to promote the inclusion of SWD in the context of SPE, in a collaborative perspective. This is a qualitative study, characterized as collaborative research. Data collection was carried out in two schools in the countryside of the state of São Paulo. The participants were three PET, their respective classes and a collaborating professor specialized in SPE. As data collection instruments, semi-structured interviews and systematic observation were used. Data treatment was based on thematic analysis and the results we illustrated in cases, according to the following categories: a) communication; b) co-planning; c) shared distribution of instruction and assessment; d) conflict resolution. In case 1 and 2, the intervention was positive, in case 3 no, due to difficulties in co-planning. It is concluded that the application of co-teaching in the Physical Education classes is possible and feasible, considering that this collaborative strategy specifically met the needs of the PET and SWD in two cases, supporting inclusion in the studied context.

Keywords: School Physical Education; Special Education; Inclusive Education; CollaborativeTeaching; People with disabilities.

\section{RESUMEN}

Desde la perspectiva de la educación inclusiva, la Educación Física escolar (EFE) ha buscado asegurar oportunidades de participación efectiva para los estudiantes con discapacidad (ECD). Sin embargo, el profesor de Educación Física (PEF) aún enfrenta muchos desafíos, igual la falta de servicios para apoyar la inclusión en su área. Luego hay interés en investigar la coenseñanza como posibilidad de apoyo al PEF. Así, el objetivo de este trabajo se centra en describir y analizar intervenciones a través de la aplicación de la co-enseñanza por parte de los agentes protagonistas (PEF, ECD y sus pares) como apoyo para promover la inclusión de DPI en contexto de EFE. Este es un estudio cualitativo, caracterizado como investigación colaborativa. La recolección de datos se realizó en dos escuelas del interior de São Paulo. Los participantes fueron tres PEF, sus respectivas clases y un profesor colaborador especializado en EFE. Como instrumentos de recolección de datos, se utilizaron entrevistas semiestructuradas y observación sistemática. El tratamiento de los datos se basó en el análisis temático y los resultados se presentaron en casos, según las categorías: a) comunicación; b) co-planificación; c) distribución compartida de instrucción y evaluación; d) resolución de conflictos. Los casos 1 y 2 fueron positivos, el caso 3 no, por dificultades en la co-planificación. Se concluye que la aplicación de la co-enseñanza en las clases de Educación Física es posible y factible, considerando que esta estrategia colaborativa atiende específicamente las necesidades del PEF y ECD en dos casos, favoreciendo la inclusión en el contexto estudiado. Palabras clave: Educación Física escolar; Educación Especial; Educación Inclusiva; Enseñanza Colaborativa; Personas con discapacidad. 
http://dx.doi.org/10.5902/1984686X65968

\section{Introdução}

O tema desta pesquisa debruça-se sobre a análise do coensino como apoio para promover a inclusão de estudantes com deficiência (ECD) no contexto da Educação Física Escolar (EFE).

A Constituição Federal de 1988 (BRASIL, 1988) e a Lei de Diretrizes e Bases (LDB) Lei no 9.394/96 (BRASIL, 1996) asseguram o direito à educação de ECD na rede regular de ensino. No ano de 1998, havia cerca de 200 mil pessoas com deficiência matriculadas na educação básica, sendo apenas 13\% em classes comuns. Em 2014, eram quase 900 mil matrículas e 79\% delas em turmas comuns de acordo com o Censo Escolar (INEP, 2016). Já em 2020, o número de matrículas da educação especial foi de 1,3 milhão, estando 1.152.875 matriculados em classes comuns e 156.025 em classes especiais (INEP, 2020). Destaca-se que o percentual de alunos incluídos em classes comuns, em 2016, era de $89,5 \%$ e, em 2020 , de $93,3 \%$, isso mostra que tem aumentado o interesse por esse modo de ensino, gradativamente, ao longo dos anos (INEP, 2020).

Segundo Mendes (2006), a inclusão é definida como a construção de um processo bilateral no qual as pessoas excluídas e a sociedade buscam, conjuntamente, promover a equiparação de oportunidades para todos, possibilitando-Ihes direito à cidadania, respeito à diversidade, aceitação e reconhecimento político das diferenças.

Com essas ações legislativas acerca da inclusão, pretende-se garantir a universalização e a equidade para todos os estudantes na rede regular de ensino. Essa ideia supõe uma mudança conceitual com referência a outros modelos, assim, prevê a passagem da escolarização dos alunos com deficiência das escolas especiais para as escolas regulares e, com isso, passam a ter convívio com crianças e jovens de sua idade (HEREDERO, 2010).

Soares e Cunha (2010) afirmam que o despreparo dos professores e demais agentes educacionais consiste em um dos principais problemas da inclusão escolar. Como consequência, grande parte desses estudantes encontra-se matriculada e frequentando classes comuns, porém sem participar efetivamente nas atividades escolares cotidianas e sem desenvolver conhecimentos sociais e acadêmicos necessários para viver de forma independente e autônoma (GLAT; PLETSCH, 2010).

O estudo de Aguiar e Duarte (2005) aponta que os professores de Educação Física (PEF) sugerem, como recursos para incluir estudantes com deficiência, ter auxílio técnico pedagógico especializado, espaço físico e material adequado, além de cursos de 
http://dx.doi.org/10.5902/1984686X65968

capacitação. Para Oliveira, Nunes e Munster (2017), a inclusão, no contexto da EFE no Brasil, deve basear-se em uma visão sistêmica que subsidie ações e deem suporte a novas formas de pensar e intervir nesse contexto.

Nesse sentido, o coensino consiste em uma estratégia colaborativa baseada na parceria entre professor do ensino comum e o professor de educação especial (ou outro professor especialista) com o propósito de lecionarem a um grupo diversificado de alunos, incluindo aqueles com deficiência ou outras necessidades especiais, na sala regular do ensino comum, de forma a atender suas necessidades de aprendizagem (FRIEND, 2008).

Brown, Howerter e Morgan (2013) corroboram essa ideia e definem o coensino como uma situação em que há um professor do ensino comum e um especialista planejando, ministrando e avaliando o conteúdo juntos em uma única sala de aula, na qual desenvolvem uma comunidade que permita que todos os alunos sejam valorizados e incluídos.

Considerando o coensino como possibilidade para a inclusão de ECD nas aulas de EF, o estudo norte-americano de Grenier (2011) teve a participação de dois professores de EF amparados por um professor de Educação Física Adaptada ${ }^{1}$ (EFA) e de dois estudantes com Síndrome de Down para participarem da atividade física de escalada junto a uma turma regular de EF. A pesquisa apontou a evolução de todos os estudantes, uma vez que houve maior envolvimento dos estudantes com e sem deficiência, além do aumento da socialização e inclusão entre eles.

Diante disso, surgem questionamentos relacionados às possibilidades, limites e como aplicar o coensino para oferecer apoio aos PEF e para a inclusão efetiva dos ECD nas escolas regulares no contexto brasileiro.

Dessa maneira, o presente estudo justifica-se pelo interesse em buscar alternativas de intervenção colaborativa que possam consistir em suporte ao processo de inclusão aos ECD no âmbito da EFE, analisando a possibilidade e a aplicação do coensino em escolas públicas brasileiras, ainda que não exista um profissional específico regulamentado no país para EFA, como mostra Oliveira e Munster (2019), considera-se um especialista em EFA um professor com formação inicial em EF, com comprovada experiência em Educação Inclusiva/Educação Especial, preferencialmente, com formação continuada na área.

Como objetivo do estudo destaca-se: descrever e analisar intervenções por meio da aplicação do coensino pelos agentes protagonistas (PEF, ECD e seus pares), enquanto apoio para promover a inclusão de ECD no contexto da EFE, sob a perspectiva colaborativa. 
http://dx.doi.org/10.5902/1984686X65968

\section{Método}

Sob perspectiva qualitativa, o estudo caracteriza-se por uma abordagem colaborativa com base em Desgagné (2007), que constitui uma visão socioconstrutivista do saber a ser desenvolvido a partir de um processo coletivo de interpretação, com base em: processo de construção colaborativa entre os parceiros envolvidos; registro da produção de conhecimentos e desenvolvimento profissional dos docentes; e contribuição para a aproximação e mediação entre a comunidade de pesquisa e escolar.

A pesquisa foi realizada em duas escolas municipais de uma cidade de pequeno porte do interior do estado de São Paulo escolhidas por critério de conveniência. Foi considerado a distância para a pesquisadora realizar a intervenção além de se ter conhecimento prévio das escolas como haver alunos com deficiência na rede regular de ensino e que participavam das aulas de Educação Física.

A seleção dos participantes compreendeu os seguintes critérios: ser PEF em escola pública; lecionar para turmas de $5^{\circ s}$ aos $9^{\circ s}$ anos do ensino fundamental; e possuir ECD frequentando suas aulas. Assim, os participantes foram três professores de EF, suas respectivas turmas e um professor especialista em EF escolar.

Foram utilizadas as siglas P1, P2 e P3 para representar os professores participantes. Para os ECD, foram utilizadas as siglas E1, E2 (sendo que havia dois ECD na turma de P2, assim foi utilizado E2a e E2b), e E3, para representá-los nos casos 1, 2 e 3 respectivamente. $O$ papel de professora especialista foi desempenhado pela professora pesquisadora (PP), a qual se enquadra nos critérios estabelecidos para a participação na pesquisa. Assim, pode-se observar as descrições dos participantes no quadro 1.

Quadro 1 - Participantes do estudo

\begin{tabular}{|c|c|c|c|c|}
\hline & Professores & Turmas & Estudante com deficiência & Deficiência \\
\hline Escola 1 & $\begin{array}{l}\text { Professora } 1(\mathrm{P} 1) \\
\text { (feminino) }\end{array}$ & $7^{\circ}$ ano & $\begin{array}{l}\text { E1 - } 13 \text { anos } \\
\text { (masculino) }\end{array}$ & $\begin{array}{c}\text { Def. Física } \\
\text { (Distrofia Muscular) }\end{array}$ \\
\hline \multirow{3}{*}{ Escola 2} & \multirow{2}{*}{$\begin{array}{l}\text { Professor } 2 \text { (P2) } \\
\quad \text { (masculino) }\end{array}$} & $5^{\circ}$ ano & $\begin{array}{l}\text { E2a }-11 \text { anos } \\
\text { (feminino) }\end{array}$ & Def. Intelectual \\
\hline & & $5^{\circ}$ ano & $\begin{array}{l}\text { E2b }-11 \text { anos } \\
\text { (feminino) }\end{array}$ & Def. Intelectual \\
\hline & $\begin{array}{l}\text { Professor } 3(\mathrm{P} 3) \\
\quad \text { (masculino) }\end{array}$ & $8^{\circ}$ ano & $\begin{array}{l}\text { E3 }-15 \text { anos } \\
\text { (masculino) }\end{array}$ & $\begin{array}{c}\text { Def. Múltipla (D.I. e } \\
\text { D.F.) }\end{array}$ \\
\hline ------- & $\begin{array}{c}\mathrm{PP} \\
\text { (feminino) }\end{array}$ & ------ & ----------- & ------------ \\
\hline
\end{tabular}

Fonte: Elaborado pela própria autora (2019). 
http://dx.doi.org/10.5902/1984686X65968

O estudo seguiu as normas para pesquisa com seres humanos de acordo com os termos da Resolução 510/16 do Conselho Nacional de Saúde, sendo aprovado pelo Comitê de Ética da Universidade Federal de São Carlos (UFSCar) pelo parecer CAEE 99681318.7.0000.5504.

A coleta de dados foi dividida em três fases: pré-intervenção, intervenção e pósintervenção, como pode ser observado na figura 1.

Figura 1 - Etapas da coleta de dados

\section{Intervenção}

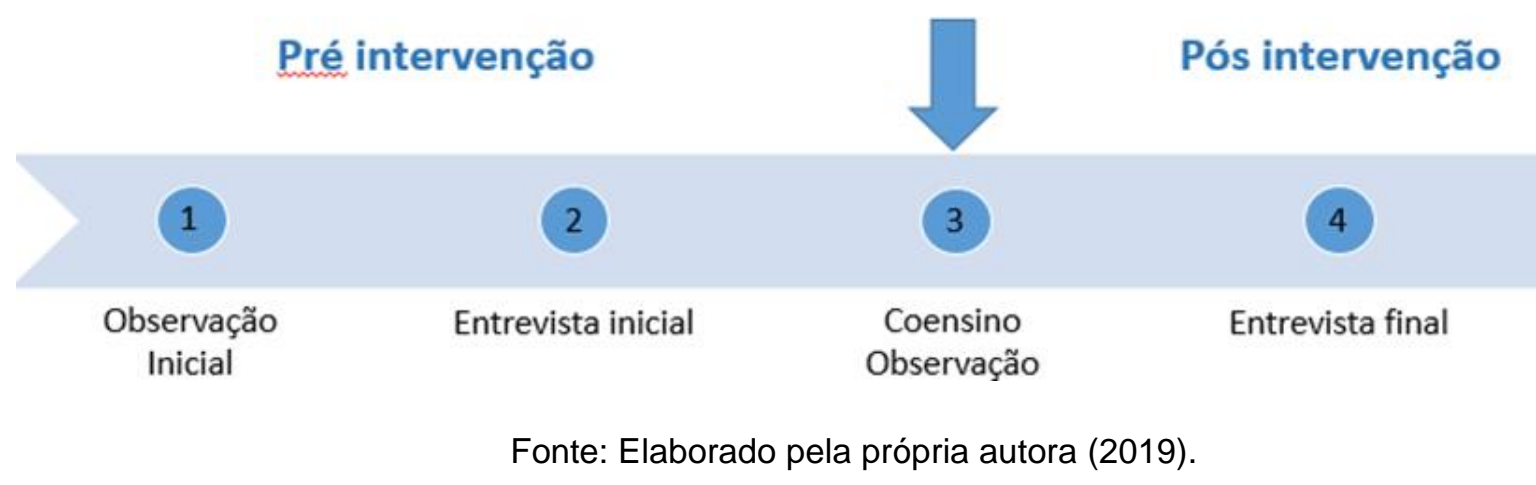

As técnicas de coleta de dados utilizadas foram: observação do tipo sistemática (MARCONI; LAKATOS, 2003), registro em diários de campo (FALKENBACH, 1987) e entrevista semiestruturada (MARCONI; LAKATOS, 2003). Para a intervenção, foi utilizado o coensino (BROWN; HOWERTER; MORGAN, 2013).

Os instrumentos, assim como o resumo dos tópicos abordados em cada um deles e quem realizou cada coleta, estão apresentados no quadro 2, junto com cada técnica.

Para a coleta de dados, contou-se com uma auxiliar de pesquisa (AP), do gênero feminino com formação em EF, a qual não consta como uma participante, pois não teve interferência na pesquisa, apenas participou sendo uma observadora externa. 
http://dx.doi.org/10.5902/1984686X65968

Quadro 2 - Coleta de dados

\begin{tabular}{|c|c|c|c|}
\hline TÉCNICA & INSTRUMENTOS & TÓPICOS & APLICAÇÃO \\
\hline $\begin{array}{l}\text { 1. Observação } \\
\text { inicial }\end{array}$ & $\begin{array}{l}\text { Roteiro de Observação } \\
\text { das Aulas de Educação } \\
\text { Física - ROA (COSTA, } \\
\text { 2015) adaptado.2; }\end{array}$ & $\begin{array}{l}\text { É constituído por } 10 \text { itens de análise para } \\
\text { obter informações acerca do processo de } \\
\text { inclusão de estudantes com deficiência } \\
\text { durante a participação das aulas de } \\
\text { Educação Física, além de como é a atuação } \\
\text { desse professor, as relações do estudante } \\
\text { com deficiência e a turma e a relação do } \\
\text { docente com o aluno com deficiência. }\end{array}$ & PP e AP \\
\hline $\begin{array}{l}\text { 2. Entrevista } \\
\text { inicial }\end{array}$ & $\begin{array}{l}\text { Roteiro de entrevista } \\
\text { inicial com o professor } \\
\text { do tipo semiestruturada. }\end{array}$ & $\begin{array}{l}\text { Contém } 28 \text { questões divididas em quatro } \\
\text { blocos: formação profissional (quatro } \\
\text { questões), atuação profissional e aluno com } \\
\text { deficiência (oito questões), processo de } \\
\text { inclusão do estudante com deficiência (oito } \\
\text { questões), e apoio pedagógico (oito } \\
\text { questões) }\end{array}$ & PP \\
\hline $\begin{array}{l}\text { 3. Coensino } \\
\text { Observação }\end{array}$ & $\begin{array}{c}\text { Observação do tipo } \\
\text { sistemática - diário de } \\
\text { campo (DC) (PP), diário } \\
\text { de campo com checklist } \\
\text { coensino } 4 \text { (AP). }\end{array}$ & $\begin{array}{l}\text { Diário de campo (PP) - bloco para } \\
\text { anotações. } \\
\text { Diário de campo com checklist coensino (AP) } \\
\text { - observar participação e interação do } \\
\text { estudante com deficiência nas aulas, as } \\
\text { relações dos profissionais, a divisão de } \\
\text { responsabilidades na execução da aula, a } \\
\text { avaliação conjunta dos professores e } \\
\text { estudante sobre a aula ministrada, a } \\
\text { resolução de conflito, além do espaço para } \\
\text { acrescentar observações extras. }\end{array}$ & PP e AP \\
\hline $\begin{array}{l}\text { 4. Entrevista } \\
\text { final }\end{array}$ & $\begin{array}{l}\text { Roteiro de entrevista } \\
\text { final com o professor } \\
\text { participante do tipo } \\
\text { semiestruturada. }\end{array}$ & $\begin{array}{l}\text { Contém } 19 \text { questões que abordam a } \\
\text { aplicação do coensino e a atuação do } \\
\text { profissional especialista. }\end{array}$ & AP \\
\hline
\end{tabular}

Fonte: Elaborado pela própria autora (2019).

Os procedimentos para coleta de dados podem ser observados no quadro 3.

Quadro 3 - Procedimentos realizados e duração na coleta de dados

\begin{tabular}{|l|l|l|}
\hline Procedimentos & Duração \\
\hline Observação inicial (ROA) & 3 semanas - 6 aulas de 50 min. \\
\hline Entrevista inicial & Após a observação inicial - 1 encontro \\
\hline $\begin{array}{l}\text { Aplicação do } \\
\text { coensino }\end{array}$ & $\begin{array}{l}\text { Comunicação } \\
\text { 1 encontro - reunião inicial. }\end{array}$ \\
\cline { 2 - 3 } & $\begin{array}{l}\text { Coplanejamento } \\
\text { Ocorria quinzenalmente, durante a Hora de Trabalho } \\
\text { Pedagógico Individualizado (HTPI) } \\
\text { min. cada, por três meses, totalizando seis encontros. }\end{array}$ \\
\cline { 2 - 3 } & $\begin{array}{l}\text { Distribuição compartilhada } \\
\text { de instrução e avaliação } \\
\text { (Observação) }\end{array}$ & $\begin{array}{l}\text { Ocorria semanalmente, sendo duas aulas de } 50 \text { min. por } \\
\text { semana, pelo período de três meses, } \\
\text { totalizando } 20 \text { aulas de intervenção com cada participante. }\end{array}$ \\
\cline { 2 - 3 } & Resolução de conflito & Não se aplicou \\
\hline Entrevista final & Após a intervenção por meio do coensino - 1 encontro \\
\hline
\end{tabular}

Fonte: Elaborado pela própria autora (2019). 
http://dx.doi.org/10.5902/1984686X65968

Para a análise dos dados, utilizou-se a análise temática (BRAUN; CLARKE, 2006) e as categorias foram definidas a priori (SILVA; GOBBI; SIMÃO, 2005) com base nas etapas da aplicação do coensino, a partir de Brown, Howerter e Morgan (2013), (quadro 4):

Quadro 4 - Etapas do coensino

Comunicação - abordar as crenças, filosofias e sentimentos com relação ao desempenho acadêmico dos estudantes, e também as perspectivas sobre funções e responsabilidades que compartilharão no coensino.

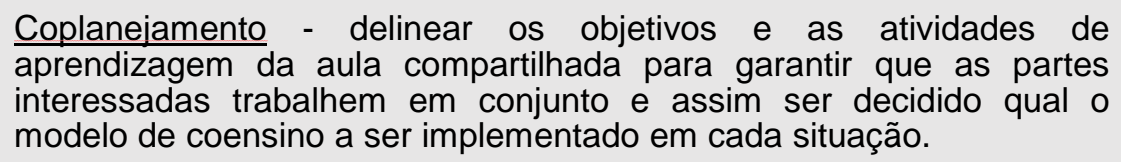

Distribuição compartilhada de instrução e avaliação - análisar os dados do estudante, orientar o desenvolvimento de novas lições, monitorar o progresso do aluno, avaliar e refletir desenvolvimento do aluno.

Resolução de conflito - desenvolver um processo de resolução de conflito que ambos os professores concordem.

Fonte: Adaptado de Brown, Howerter e Morgan (2013).

Para assegurar a fidedignidade e aumentar a validade interna do estudo, recorreu-se aos seguintes procedimentos propostos por Brantlinger et al. (2005): checagem dos dados coletados da transcrição da entrevista pelo participante entrevistado; triangulação - uso de mais de um instrumento de coleta de dados (entrevista inicial e final e diário de campo); e checagem por pares.

\section{Resultados}

Os resultados serão apresentados por meio dos casos 1, 2 e 3, considerando as especificidades de cada situação, bem como as demandas dos professores participantes e as dos respectivos estudantes. 
http://dx.doi.org/10.5902/1984686X65968

\section{Caso 1}

a) Comunicação

Com base na entrevista inicial, no ROA e no DC da reunião inicial, foi estabelecido o vínculo entre P1 e PP e levantadas as seguintes informações sobre as dificuldades apresentadas por P1: tempo escasso para planejar as aulas, falta de capacitação para trabalhar com E1, dificuldade de ensinar movimentos específicos e resistência de E1 em participar de novas atividades propostas.

Na entrevista inicial, P1 afirma: "Eu queria ter mais tempo pra pesquisar mais coisas, eu dou aula o dia todo, então é muito difícil”. P1 admite suas limitações no planejamento da atividade: "Com tanta aula que eu tenho, eu não preparava as aulas".

O trecho da entrevista foi constatado pela PP e AP por meio das observações registradas no ROA (14/03/19), no qual os alunos pediam uma atividade inicial (no caso a Queimada $^{7}$ ) e a professora precisou se ausentar para ir buscar a bola de borracha para 0 jogo, indicando que não se havia planejado para aplicar essa atividade com antecedência. O ROA (28/03/19) informa que a aula consistiu em troca de passes do handebol, dois a dois, com deslocamento. P1 demonstrou não saber como envolver E1 na atividade. A solução partiu dos estudantes, que optaram por realizar a atividade em trio: dois estudantes alternavam-se entre, conduzir a cadeira e realizar a troca de passes com o E1. Também foi observado, pela PP e AP, e registrado no ROA (14/03 e 28/03), que P1 mantinha um padrão nas aulas de EF: a sessão iniciava-se com aquecimento baseado em jogos pré-desportivos, na parte principal, eram ensinados os fundamentos de determinada modalidade e, na parte final, era realizado o jogo propriamente dito.

Assim, entendendo a estrutura da aula e sua metodologia e tendo a aproximação com $\mathrm{P1}$, pode-se implementar as etapas subsequentes do coensino.

b) Coplanejamento

Utilizando o plano de ensino do município sobre o conteúdo que deveria ser abordado, foram discutidas quais unidades seriam desenvolvidas, sempre com sugestões, ideias e análise da adequação da atividade à faixa etária e ao perfil da turma. As reuniões eram voltadas para o coplanejamento, além disso, eram feitas breves conversas semanais, após cada aula, para discussão e retomada do planejamento para a próxima aula, de acordo com o desenvolvimento das atividades do dia. 
http://dx.doi.org/10.5902/1984686X65968

Por meio de diálogo e com base nas anotações em DC, discutia-se como havia sido o interesse e a participação de todos os estudantes da turma nas atividades das aulas anteriores. Em seguida, era conversado sobre o interesse em repetir alguma atividade, ou adaptá-la para obter uma maior participação, ou se havia necessidade de alteração de alguma estratégia de ensino, materiais, etc., visando a atingir algum objetivo que porventura não tivesse sido contemplado.

Depois das atividades definidas, eram discutidas as estratégias para ensinar e realizar cada atividade assim como quais materiais seriam necessários para implementá-las.

c) Distribuição compartilhada de instrução e avaliação

Com relação à execução do coensino, foi um processo viável tanto para $\mathrm{P} 1$ como para $\mathrm{PP}$, obtendo-se resultados significativos mesmo no período curto de intervenção com duração de três meses.

Observou-se que, no momento da aula, seguia-se o planejado e cada professor realizava seu papel espontaneamente. Caso a atividade fosse realizada em dois grupos, cada um se dirigia para um lado da quadra. Se fosse em roda, um explicava e o outro auxiliava e, assim, as funções eram pré-estabelecidas de acordo com a atividade, mas também considerando a necessidade da prática.

Uma atividade considerada exitosa ocorreu no ensino do conteúdo basquetebol. Segundo o planejamento, a turma seria dividida em dois grupos, ficando um com cada professora, em um dos lados da quadra para a realização do arremesso na tabela. Previamente, como possibilidade de adaptação para possíveis dificuldades, também foram separadas bolas de vôlei e de borracha, além de bambolê. Após a explicação e o início da atividade de arremesso, alguns alunos (entre eles E1) apresentaram dificuldade em executar o movimento, pois devido ao peso da bola de basquetebol, não possuíam força necessária para lançá-la à altura da tabela. Em comum acordo, foi proposta a variação da atividade, utilizando bolas mais leves e o bambolê como aro mais baixo para não desmotivar esses alunos e possibilitar o aprendizado de todos. P1 seguiu com a atividade inicial e PP realizou a variação da mesma atividade. Com a evolução de cada um e a compreensão do movimento, o nível de dificuldade era aumentado, gradativamente, e os alunos tinham a opção de transitar entre as duas atividades livremente. Dessa maneira, o planejamento foi seguido, a aula foi organizada e oportunizou a todos a realização e o interesse pela atividade e pelo conteúdo proposto para a aula, conforme registrado no DC 
http://dx.doi.org/10.5902/1984686X65968

de PP (27/06): “A parceria com a outra profissional, a colaboração, aplicação das etapas do coensino e realização das atividades foram positivas, produtivas e agradáveis. Ao final, o vínculo ia além da sala de aula." E no DC de AP (27/06): "As duas (P1 e PP) se dão muito bem, é uma relação tranquila. Dividem bem a sala. Há muito diálogo e a aula é organizada e estruturada."

$\mathrm{Na}$ entrevista final, P1 relata: "Pra mim foi interessante porque eu me senti mais segura." A modificação na atitude de P1 também foi registrada no DC da PP, pois P1 passou a demonstrar mais confiança na atuação, nas escolhas das atividades e propostas de adaptações ao ECD. P1 atribui tal mudança à intervenção colaborativa:

\begin{abstract}
Foi muito importante porque a professora [especialista/pesquisadora] ajudou bastante, ela é muito participativa, ela gosta muito disso, dá pra ver que é o trabalho dela. Tomara que ela se realize nisso porque tem muitas crianças que precisam disso e foi pra mim uma experiência muito boa também, tanto na preparação das aulas, como na execução, adaptação de atividades, materiais, tudo. /.../ E tem muito resultado. (Entrevista final)
\end{abstract}

A coavaliação ocorria durante a execução das atividades cotidianas da aula e no momento do coplanejamento, quando discutidas as observações e anotações por P1 e PP. Considerava-se, como parâmetro, a participação e o interesse do E1 e dos demais estudantes nas aulas, além da sua evolução na realização das atividades propostas, se conseguiam atingir o objetivo proposto, sempre atentando para aspectos motores, sociais e afetivos.

As professoras observam e comentam sobre as dificuldades e potencialidades de todos os estudantes durante as atividades, principalmente durante os jogos. Trocam ideias e fazem correções ou elogios a todos os estudantes. Sempre fornecem feedback aos alunos. (DC - AP- 23/05)

Na entrevista final, P1 refere-se à melhoria na participação e no envolvimento dos alunos com as atividades propostas: "Os alunos participavam de todos os jogos, todos se empenhavam na participação de qualquer atividade".

O DC da PP reforça a percepção de P1:

Fizeram o jogo de queimada e o melhor amigo de E1 estava no outro time (PP ofereceu apoio físico conduzindo a cadeira de rodas), competiu com seus colegas em igualdade, sendo queimado e fazendo tentativas de queimar, da mesma maneira que seus pares. Por seu melhor amigo estar no outro time, tentavam se queimar e disputavam quem iria ganhar. (30/05)

d) Resolução de conflito

Não foi necessário recorrer a essa etapa. 
http://dx.doi.org/10.5902/1984686X65968

\section{Caso 2}

a) Comunicação

As dificuldades de P2, identificadas durante o período de observação inicial, foram: aproximação em relação a E2a e E2b nas aulas, promoção da participação desses alunos, falta de compreensão das regras nas atividades e conciliação da atenção que E2a e E2b demandavam com a atenção demandada pela turma. Os relatos de P2, na entrevista inicial, confirmam esse registro: "E2a e E2b participavam pouco, cansam rápido.”.

/.../ principalmente em me aproximar. /.../ É um pouco mais difícil esse processo com os alunos com deficiência, até conhecer, saber o que eles conseguem fazer... E são mais inseguros, tímidos, reservados, e necessitam mais atenção. Seria principalmente nessa parte social, de ter tempo e dedicar mais atenção a eles [aos ECD].

Também pode ser observado, inicialmente pela AP e PP, que E2a e E2b ficavam sempre juntas e não participavam da atividade. Quando o faziam (pois o professor tentava inseri-las nas atividades) E2a parava no início da atividade e/ou era resistente a realizá-la. E2b a acompanhava.

b) Coplanejamento

Entre os três participantes do estudo, P2 foi o que mais se envolveu com a fase de coplanejamento. Além de utilizar o plano de ensino do município para a elaboração das aulas e atividades subsequentes, a troca de ideias e de experiências ocorridas foram muito ricas, o que facilitou o processo de colaboração.

Destaca-se que o conteúdo programático previsto para o nível de ensino em questão (5ano) possui característica mais lúdica e menos esportivista, favorecendo a flexibilização curricular e possibilitando atividades mais inclusivas. Assim, realizaram-se menos adaptações das atividades do que nos casos 1 e 3.

Outro ponto foi com relação ao conteúdo pré-desportivo de vôlei (trabalhado na $4^{\underline{a}}$ e $5^{\underline{a}}$ aulas), que não estava no cronograma para o semestre da intervenção, mas que foi nele incluído porque os professores da rede têm liberdade e flexibilidade para trabalharem os conteúdos como preferirem. Por meio da comunicação e troca de experiências, P2 pediu para ser trabalhado, pois PP tem domínio nessa temática, ao contrário de P2.

Para P2, esse momento foi significativo e o mais importante na implementação do coensino, conforme pode ser observado em sua fala: 
http://dx.doi.org/10.5902/1984686X65968

Planejamento e organização foi o ponto mais alto e depois, na realização, nós organizamos e fizemos o cronograma. Foi só seguir e fluiu bem. Todas fluíram muito bem, mas acho que a base que é o planejamento e a organização foram os que mais influenciaram e são mais importantes pro resto dar certo. (Entrevista final)

c) Distribuição compartilhada de instrução e avaliação

A aplicação do coensino iniciou-se com um pouco de receio por parte de P2, pois o mesmo havia relatado experiência anterior negativa, com profissionais que interferiram em seu trabalho e que não eram da área de EF.

Tive experiência de um médico que prescreveu exercícios físicos para um paciente, meu aluno, sendo que ele não é um profissional dessa área, e isso interferiu no meu trabalho. /.../ Aí até atrapalha e dificulta trabalhar. Nesses casos que não tem diálogo, não é legal realizar parceria. (Entrevista inicial)

/.../ Outro professor, pedagogo, talvez daria certo, não sei. Eu acho ajudaria mais no sentido de dar atenção, no caso das alunas com D.I. motivá-las a participarem e se soltarem, perderem a timidez, socializarem mais. Ahh... quando elas saem da atividade e eu as chamo e não voltam fica difícil. (Entrevista inicial)

Porém, logo nas primeiras aulas, P2 ficou mais à vontade com PP e a relação entre eles melhorou e foi positiva, como pode ser observado na entrevista final: "No primeiro dia, senti uma insegurança, não foi nem dificuldade, foi só por não conhecer direito, saber como seria, aí depois fluiu.".

/.../ foi um auxílio e tanto. Foi mais do que eu podia imaginar, me ajudou com a participação e a timidez das meninas (D.I.) que era o que eu esperava, e me ajudou em muito mais coisa, nas aulas como um todo, com todos os alunos, desde o planejamento execução, correção, avaliação, foi um ótimo auxílio. E os alunos também gostavam. Deixa a aula mais dinâmica, mais leve. (Entrevista final)

A $3^{\text {a }}$ aula não seguiu o planejado, pois essa turma tem 25 alunos e, nesse dia, muitos alunos faltaram. Se mantivesse o programado, boa parte dos estudantes perderia o início de um novo conteúdo, além da atividade planejada previamente necessitar de mais alunos para a montagem de grupos e ter boa dinâmica. Assim, ocorreu diálogo entre P2 e PP, no início da aula, e as atividades foram modificadas.

Existe uma divisão da aula, porém percebi que não teve um planejamento entre eles. O que dificultou o trabalho do outro professor (PP), que, por sorte, parecia conhecer as atividades. Observei que quando as meninas não quiseram participar, ela (PP) soube adaptar, mas foi improvisado. Mas (as meninas) não ficaram sentadas. (DC - AP - 24/04)

A intervenção de PP em relação à atuação de $\mathrm{P} 2$, nas aulas ministradas conjuntamente, foi de acordo com a necessidade de E2a e E2b e de P2, como observado 
http://dx.doi.org/10.5902/1984686X65968

no DC de AP (05/06) "A relação de PP e P2 é ótima e um complementa o outro. O revezamento e atenção que cada um fornece para a turma são de grande valia e percebe que os alunos escutam e valorizam ambos os professores sem distinção.".

O revezamento da atuação de cada professor nesse modelo é interessante. E destaca-se nos jogos pré desportivos como no pique bandeira, no qual cada um (PP e P2) participou em um grupo, tornando-o produtivo nas aulas, possibilitando criar uma aproximação maior com todos os estudantes e ensinando táticas e técnicas durante a atividade, por meio de demonstração, suporte verbal ou físico, quando necessário. (DC - PP - 24/04)

A coavaliação ocorreu por meio de diálogo entre P2 e PP, durante as atividades e observação da evolução individual e coletiva dos estudantes durante as práticas. Ao final das aulas, havia um breve diálogo e anotações de pontos para serem abordados na próxima reunião, além de dados sobre a evolução ou dificuldade dos estudantes, para serem retomados, conforme relatado por AP:

Observei PP e P2 conversando e trocando ideias a respeito de qual aluno apresentava mais facilidade, ou dificuldade, e como estavam participando. Analisaram conjuntamente a participação, desenvolvimento e aprendizagem dos estudantes por meio de observação e comparação. (DC12/06)

Havia bastante diálogo entre eles (P2 e PP) nos finais das aulas, quando avaliavam as atividades e a participação dos alunos. Durante as atividades forneciam retorno aos estudantes, reforçavam com elogios os que conseguiam realizar o proposto. Procuravam motivar e por vezes auxiliar os alunos que não conseguiam, ou possibilitando alternativas que permitissem o aluno obter êxito. (DC08/05)

d) Resolução de conflito

Não foi necessário recorrer a essa etapa.

\section{Caso 3}

a) Comunicação

Mesmo tendo P3 aceitado participar da pesquisa, houve pouco envolvimento e dificuldade de diálogo com esse participante. A maioria das informações foi obtida por meio de observações, considerando que P3 não demonstrava muito interesse em conversar com PP.

Assim, as dificuldades que emergiram durante a observação inicial das aulas de P3 foram: participação de E3 nas atividades e inclusão de E3 pela turma. 
b) Coplanejamento

Foi difícil implementar o coplanejamento em parceria com P3, pois, mesmo acordado que ocorreria quinzenalmente no HTPI, não houve adesão por parte do participante. Destaca-se que P3 e P2 atuam na mesma escola, portanto, compartilham da mesma equipe gestora que incentivou e valorizou esse momento pedagógico. Contudo, por estar há muito tempo nessa instituição, P3 acabava envolvendo-se com várias funções extras, como furar parede, montar um armário, entre outras. Sendo assim, P3 utilizava suas aulas vagas e o HTPI para dar suporte às demandas extras as suas funções escolares.

Em algumas reuniões, a PP acompanhou P3 nessas funções, mantendo com ele um diálogo informal para discutir como estavam as aulas, as atividades, os alunos e o que seria realizado nas próximas aulas. Em outras reuniões, foi possível realizar o coplanejamento no horário combinado do HTPI, de maneira tranquila e com exclusiva dedicação de P3.

No entanto, mesmo havendo encontros ocasionais destinados ao coplanejamento, percebia-se uma falta de comprometimento por parte de P3 com essa etapa da intervenção. No decorrer da pesquisa, de acordo com o observado pela PP e AP, acerca do perfil e da prática de $\mathrm{P} 3$, verificou-se que $\mathrm{P} 3$ não possuía hábito de planejar suas aulas ou preparar as atividades com antecedência, o que dificultou o trabalho de PP e, consequentemente, interferiu na aplicação e efetivação do coensino.

c) Distribuição compartilhada de instrução e avaliação

P3 não seguia o plano de ensino do município e as poucas aulas coplanejadas não chegavam a ser aplicadas. Assim, devido às dificuldades de coplanejamento ou a não execução do planejado quando ocorria, a intervenção e aplicação do coensino tornaram-se inviáveis.

Entretanto, P3 mantinha uma rotina padrão das aulas e permitia que a PP interviesse no apoio direto aos estudantes. Desse modo, PP passou a realizar atividades com E3 e com os estudantes que não se envolviam nas aulas de EF. Isso acontecia por meio de adaptações e improvisação de atividades paralelas, exercendo, assim, a função de apoio suplementar a E3 e seus colegas.

Considerando que não houve troca ou desenvolvimento de um trabalho conjunto com P3, pode-se dizer que não ocorreu coensino e a intervenção se limitou à assistência individualizada a E3. Como não ocorreu distribuição compartilhada de instrução, o processo de avaliação também foi comprometido. 
d) Resolução de conflito

Dada a dificuldade em estabelecer comunicação com P3, considerou-se infrutífera a possibilidade de manter diálogo e aprofundamento das discussões sobre o coensino. Para evitar desgaste ou exposição desnecessária do participante e qualquer atrito na relação com o voluntário da pesquisa, PP optou por ajustar sua intervenção à forma como o P3 estava acostumado a trabalhar, atuando como uma assistente e não como professora colaboradora especialista em EFE.

\section{Discussão}

Após a apresentação dos três casos separadamente, a discussão será desenvolvida de forma conjunta dentro de cada uma das categorias.

\section{a) Comunicação}

Os resultados apresentados por P1, P2 e P3 indicam dificuldades semelhantes às apresentadas em estudos voltados para a inclusão de pessoas com deficiência nas aulas de EFE, como será discutido a seguir. Assim, nesse estudo, foram levantadas as seguintes dificuldades por parte dos professores: a) pouco tempo para planejamento, b) formação profissional insuficiente para lidar com essa população e, c) conciliação da atenção dada a todos os alunos (número excessivo de alunos por turma) com a atenção dada aos ECD. Em relação ao aluno com deficiência, com base no relato dos participantes e nas observações: a) resistência em participar das aulas, b) dificuldade na realização das atividades exigidas nas aulas.

Acerca dos impasses apresentados pelos participantes dessa pesquisa, Fiorini (2011) e Fiorini e Manzini (2014) destacam a dificuldade no planejamento, na execução da aula e a escassez ou ausência de recursos específicos para o trabalho com ECD nas aulas de EF, semelhante ao apontado e observado com P1, P2 e P3, neste estudo.

Com relação à formação para lidar com os alunos, como aparece no Caso 1 deste trabalho, Souza e Resende (2019) apontam que o professor não deve se prender a sua formação acadêmica e necessita ir em busca de auxílio para a sua prática, visando às potencialidades do estudante e não suas limitações apresentadas por sua condição de aluno com deficiência.

Ainda sobre os pontos apresentados pelos participantes, Batista e Metzner (2018) também trazem em seu trabalho que, mesmo quando os professores de EF possuem 
conhecimento sobre a inclusão de ECD, necessitam de apoio em relação à educação inclusiva, apontando auxílio profissional e capacitações como sugestões de recursos para melhorar o seu trabalho. Outra informação trazida pelos participantes do estudo de Batista e Metzner (2018) e também no trabalho de Muller (2010) é com relação ao número excessivo de alunos em uma turma e a dificuldade de trabalho que isso implica, o que foi mencionado por P1 e P2 neste estudo.

No que se refere à participação dos discentes, Teixeira, Bergmann e Copetti (2019) mostraram, em seu estudo realizado com quatro ECD (Síndrome de Down) de uma escola privada e duas escolas públicas, que, apenas os dois alunos que frequentavam a escola privada participavam da aula de EF. Já em relação aos dois estudantes que não participavam, um dos motivos era por falta de interesse do aluno, o que era respeitado por seus responsáveis; assim como ocorria, inicialmente, no Caso 2 deste estudo, pois as alunas não tinham interesse em participar e/ou se cansavam rapidamente da atividade.

Outro aspecto apontado no estudo de Teixeira, Bergmann e Copetti (2019) é que as duas estudantes que participavam da aula de EF não a faziam efetivamente e um dos motivos era a abordagem do PEF e a escolha e organização dos conteúdos, o que se assemelha ao ocorrido com P3 neste estudo: o conteúdo era esportivista e as aulas não eram planejadas, assim não possibilitavam a participação e inclusão do estudante com deficiência nas aulas de EF.

Para muitos ECD, a aula de EF pode não ser uma experiência positiva, uma vez que podem enfrentar dificuldades de interação com os pares, marginalização e não interação com os professores (BLINDE; CALLISTER, 1998; GOODWIN; WATKINSON, 2000; HUTZLER et al., 2002). Porém, a experiência negativa na EFE pode ser evitada quando se revê algumas questões, como as estratégias utilizadas, a intervenção do professor e o trabalho com toda escola visando à colaboração, como pode ser observado nos Casos $1 \mathrm{e}$ 2 deste trabalho.

Visando a esse contexto de participação e inclusão do estudante com deficiência nas aulas de EF, Fiorini e Manzini (2019) sugerem que os professores utilizem as estratégias de ensino específicas, que são indicadas para cada tipo de deficiência, junto com as generalizáveis, que são indicadas para todos os tipos de deficiência. Tal procedimento pode ampliar o interesse e a participação desses estudantes na EF.

Os relatos das dificuldades encontradas por P1 e P2 mostram como há barreiras no processo de inclusão de alunos com deficiência nas aulas de EF. Além disso, pode-se 
http://dx.doi.org/10.5902/1984686X65968

destacar a importância do professor para a participação e o desenvolvimento do aluno com deficiência, junto com a necessidade de planejar as atividades, organizar seus conteúdos e pensar em variações e adaptações que possibilitem um melhor aproveitamento e inclusão desses estudantes nas aulas.

b) Coplanejamento

Nessa categoria de aplicação do coensino, P1 e P2 tiveram vários pontos convergentes que possibilitaram a aplicação das etapas seguintes (distribuição compartilhada de instrução e avaliação; e resolução de conflito) do coensino. Apenas no caso 3 não foi possível estabelecer o coplanejamento, considerando a dificuldade de P3 em aderir a essa etapa essencial.

Com P1 e P2, o coplanejamento ocorria quinzenalmente, durante 50 minutos, e brevemente após as aulas de intervenção. Acerca da importância desses momentos, Silva, Santos e Fumes (2014) traz em seu estudo que, para a colaboração ser efetiva e possível em um ambiente escolar, é necessário ocorrer encontros entre os participantes com uma frequência pelo menos quinzenal. Acrescenta-se ainda que, caso não seja possível realizar essas conversas, por mais que ambas as partes tenham interesse na colaboração, a paridade torna-se inviável.

Segundo Menegolla e Sant'Anna (2001), o planejamento pode ser definido como:

Um instrumento direcional de todo o processo educacional, pois estabelece e determina as grandes urgências, indica as prioridades básicas, ordena e determina todos os recursos e meios necessários para a consecução de grandes finalidades, metas e objetivos da educação. (p. 40)

Nesse sentido, o planejamento é considerado um momento importante na organização do trabalho pedagógico do professor. Por mais que, em seu início, o planejamento tenha sido visto como um regulador das ações pedagógicas, hoje ele é reconhecido como um facilitador dos trabalhos desses profissionais. Ele permite 0 questionamento do tipo de cidadão que se pretende formar e, assim, torna-se ato políticofilosófico, científico e técnico (CASTRO; TUCUNDUVA; ARNS, 2008). Desse modo, considerando a importância do planejar a atividade, Gardin (2004) complementa que essa é uma ferramenta que proporciona eficiência à ação humana, pois organiza a tomada de decisões. Assim, um dos fatores primordiais para o sucesso do coensino é o coplanejamento, no qual os professores precisam ter tempo de planejar em conjunto (LEHR, 1999). Isso foi observado e possível de ser realizado com P1 e P2, permitindo a 
http://dx.doi.org/10.5902/1984686X65968

sequência da tomada de decisões e o desenvolvimento da etapa seguinte, que foram as aulas coensinadas e a coavaliação.

Mesmo com P1 relatando, inicialmente, que uma de suas dificuldades era não ter muito tempo para planejar suas atividades e que, às vezes, acabava cumprindo algumas funções que não eram compatíveis ao HTPI, a partir do momento em que foram marcados os encontros, a gestão sempre os apoiou. Sendo assim, esse horário era utilizado para o planejamento das aulas de maneira conjunta.

Em relação aos encontros para decisões pedagógicos, Martins (2002) mostra que os professores das escolas brasileiras têm momentos de organização, como conselhos de classe, horários de trabalho pedagógico coletivo e grupos que ministram as mesmas disciplinas. Entretanto, muitas vezes, esses momentos, que deveriam ser de reflexão, planejamento, criação e transformação da prática educacional em atividades humanizadoras para os docentes e estudantes, são utilizados para fins burocráticos e resoluções de problemas emergenciais.

A colocação de Martins (2002) coaduna-se com os dados evidenciados pelo caso 3, uma vez que P3 não demonstrava comprometimento adequado com esse horário de trabalho; pois, em várias ocasiões, P3 priorizava o atendimento a outras demandas da escola, negligenciando o espaço de dedicação ao aprimoramento de sua prática educacional.

Ferreira (2016) destaca a gestão escolar como um elemento importante e fundamental para a superação de conceitos culturais e dogmáticos que acabam recaindo sobre 0 indivíduo, dificultando práticas que favorecem a inclusão, como a efetividade do trabalho colaborativo. E destaca que, por meio desse trabalho, é possível proporcionar espaços de formação inicial e continuada aos professores, permitindo-lhes contribuir e construir conjuntamente com estratégias para a valorização de cada aluno na educação básica e, assim, proporcionar, por meio da equiparação, oportunidades a todos os alunos nas aulas de EF (FERREIRA, 2016).

Ainda sobre gestão escolar é interessante pontuar que, embora P2 e P3 pertencessem à mesma escola, as atribuições designadas a eles, pela equipe gestora, diferiam bastante. Por estar em início de carreira e ser mais novo na instituição, P2 parecia estar mais empenhado em investir na qualidade didática de seu trabalho. Todavia, isso não pode ser afirmado de P3, pois, após tantos anos de exercício profissional e permanência na instituição, P3 já não demonstrava a mesma disposição para se dedicar ao planejamento e à intervenção pedagógica. 
http://dx.doi.org/10.5902/1984686X65968

No entanto, conforme indicado por Arguelles, Hughes e Schumm (2000), Ferreira (2016) e Brown, Howerter e Morgan (2013), a não realização do coplanejamento acabou inviabilizando a aplicação da próxima etapa do coensino, no caso 3.

c) Distribuição compartilhada de instrução e avaliação

A terceira etapa de implementação do coensino junto a P1 e P2 foi orientada pelos princípios propostos por Brown, Howerter e Morgan (2013). Nestes casos, foi possível estabelecer a paridade, o trabalho horizontal e a colaboração entre os professores (PP e P1; e PP e P2), com base em Friend (2017) e Silva, Santos e Fumes (2014).

Acerca das relações entre professor e profissional de apoio, Rodrigues (2003) aborda uma realidade existente em Portugal para fazer uma reflexão relativa à realidade vivenciada pelos professores de EF do Brasil que é, em termos genéricos, o apoio dado por profissionais que não são da mesma área disciplinar, o que cria dificuldades para que o PEF encontre parceria com o outro professor, impedindo, assim, a efetividade desse serviço de apoio oferecido. Talvez, por esse motivo, P2 tenha relatado insegurança inicial em aceitar o apoio de PP. Entretanto, logo no início, P2 identificou-se com a proposta da pesquisa e demonstrou disposição em participar, favorecendo o processo de implementação do coensino, diferentemente do que ocorreu com P3. Este, que pareceu estar aberto no início, não estava disposto a modificar sua prática, atualizar-se e realizar a paridade, assim como planejar conjuntamente e aplicar o elaborado nas aulas práticas.

Assim, observou-se que as aulas de P3 foram voltadas para o rendimento, no qual os conteúdos da EF são o ensino de técnicas e táticas esportivas. Aqui, o professor faz o papel de técnico e os alunos são vistos como atletas, uma concepção da EF bastante enfatizada na década de 40 (CASTELLANNI FILHO, 1994).

\footnotetext{
A indisposição de P3 em modificar sua prática e adaptar as atividade de EF com apoio de PP são ações que favorecem a exclusão funcional, apontada por Trip, Rizzo e Webbert (2007), como a ausência de oportunidades adequadas para uma aprendizagem eficaz, impedindo a participação de ECD, podendo afetar negativamente sua participação e engajamento em aulas de EF.
}

Os professores, muitas vezes, apresentam uma visão negativa ao trabalhar com alunos com deficiência, isso pode ocorrer pela falta de apoio para subsidiar o PEF em sua prática (STELLA; SEQUEIRA, 2013).

d) Resolução de conflito

Não se aplicou ao estudo. 
http://dx.doi.org/10.5902/1984686X65968

\section{Considerações finais}

A partir dos resultados e das especificidades apresentadas nos casos 1 e 2, foi possível demonstrar a viabilidade e efetividade da aplicação do coensino nas aulas de EF. Em dois dos três casos discutidos no presente artigo, as necessidades dos participantes da pesquisa foram supridas, favorecendo a participação e a inclusão efetiva dos ECD nas aulas de EF. Nos dois primeiros casos, considera-se que os ECD tiveram acesso aos conteúdos curriculares e à oportunidade de participar equanimemente das atividades propostas, usufruindo benefícios em seu desenvolvimento motor, social e afetivo.

O processo de aplicação do coensino nas aulas de EF manteve um padrão, o que permite a replicação e implementação em outras escolas e municípios. Destaca-se, todavia, que a falha em desenvolver alguma das etapas previstas nesse processo, conforme reportada a dificuldade de planejamento ocorrida no caso 3, implica na inviabilização da implementação das etapas subsequentes.

No entanto, prevendo que, em futuras pesquisas, situação como a ocorrida no caso 3 podem se repetir, sugere-se que seja realizada uma capacitação dos profissionais envolvidos no processo para a aplicação do coensino.

Assim, pelo fato dos ECD, muitas vezes, ainda não estarem efetivamente incluídos nas aulas de EF e dos PEF apresentarem dificuldades em trabalharem com esses estudantes como foi mostrado nos resultados, esta pesquisa traz perspectivas para um novo apoio aos PEF e novas possibilidades de inclusão dos ECD nas aulas de EF por meio do coensino nas escolas brasileiras e, desse modo, a implementação da cultura colaborativa no ambiente escolar.

\section{Referências}

AGUIAR, João Serapião de; DUARTE, Édison. Educação inclusiva: um estudo na área da educação física. Rev. Bras. Ed. Esp., Marília, v.11, n.2, p.223-240, Mai-Ago. 2005.

ARGÜELLES, Maria Elena; HUGHES, Marie Tejero; SCHUMM, Jeanne Shay. CoTeaching: A Different Approach to Inclusion. Principal Reston, Flórida, v. 79, n. 4, p. 50 51, 2000. 
BATISTA, Kátia Sisdeli; METZNER, Andréia Cristina. Formação Profissional Diante da Inclusão de Alunos com Deficiência nas Aulas de Educação Física: a percepção dos professores. Revista Educação Física UNIFAFIBE, Bebedouro/SP, vol. 6, p. 136-155, set., 2018. Disponível em:

http://unifafibe.com.br/revistasonline/arquivos/revistaeducacaofisica/sumario/73/14092018 191051.pdf. Acesso em: 03 de nov. 2020.

BLINDE, Elaine; McCALLISTER, Sarah. Listening to the voices of students with physical disabilities. Journal of Physical Education, Recreation and Dance, vol. 69, n. 6, p. 6468, 1998. Disponível em: https://doi.org/10.1080/07303084.1998.10605578. Acesso em: 17 fev. 2019.

BRANTLINGER, Ellen; JIMENEZ, Robert; KLINGNER, Janette, et al. Qualitative Studies in Special Education. Exceptional Children, vol. 71, n.2, p.195-207, 2005.

BRASIL. Ministério da Educação. Censo Escolar 2017: notas estatísticas. Brasília, DF, 2018. 60p.

BRASIL. Ministério da Educação. Censo Escolar da Educação Básica 2020: educação especial. Brasília, DF, 2019. 74p.

BRASIL. Ministério da Educação. Lei de Diretrizes e Bases da Educação Nacional. Brasília, DF, 1996. 289p.

BRASIL. Ministério da Educação. Programa de implantação de salas de recursos multifuncionais. Brasília, DF, 2009. [n.p.]

BRASIL. Presidência da República. Lei no 12.796, de 4 de abril de 2013. Brasília, DF, 2013. 120p.

BRASIL. Senado Federal. Constituição da República Federativa do Brasil. Brasília, DF, 1988. 498p.

BRAUN, Virginia; CLARKE, Victoria. Using thematic analysis in psychology. Qualitative Research in Psychology, Virginia, vol. 3, n. 2. p. 77-101, 2006. Disponível em: http://dx.doi.org/10.1191/1478088706qp063oa. Acesso em: 10 de nov. 2019.

BROWN, Nancy Beyers; HOWERTER, Catherine S.; MORGAN, Joseph John. Tools and Strategies for Making Co-teaching Work. Rev. Intervention in School and Clinic. v. 49, n. 2, p.84-91. 2013.

CASTELLANI FILHO, Lino. Educação Física no Brasil: a história que não se conta. 4 ed. Campinas: Papirus, 1994.

CASTRO, Patrícia Aparecida Pereira Penkal de; TUCUNDUVA, Cristiane Costa; ARNS, Elaine Mandelli. A importância do planejamento das aulas para organização do trabalho do professor em sua prática docente. Athena - Revista Científica de Educação, Curitiba, v. 10, n. 10, p. 49-62, jan./jun. 2008. Disponível em: file://C:/Users/Mel/Downloads/Artigo_A_import\%C3\%A2ncia_do_planejamento_das_aulas_para_organi\%20(1).PDF. Acesso em: 03 de nov. 2019. 
COSTA, Camila de Moura. Inclusão de estudantes com deficiência visual nas aulas de Educação Física: um estudo de caso. 2015. 2012 f. Dissertação (Mestrado em Educação Especial) - Programa de Pós-Graduação em Educação Especial, Universidade Federal de São Carlos, São Carlos, 2015.

DESGAGNÉ, Serge.; O conceito de pesquisa colaborativa: a ideia de uma aproximação entre pesquisadores universitários e professores práticos. Revista educação em Questão, Natal, v. 29, n. 15, p. 7-35, ago., 2007.

FALKEMBACH, Elza Maria Fonseca. Diário de campo: um instrumento de reflexão. In: Contexto e educação, ljuí, vol. 2, n. 7, jul./set., p. 19-24, 1987.

FERREIRA, Robson Alex. Trabalho colaborativo na educação física escolar: estratégias para a formação de professores e inclusão. 2016. 181f. Tese (Doutorado em Educação) - Programa de Pós Graduação em Educação, Universidade Estadual Paulista - UNESP, Presidente Prudente, 2016.

FIORINI, Maria Luiza Salzani. Concepção do professor de Educação Física sobre a inclusão do aluno com deficiência. 2011. 143 f. Dissertação (Mestrado em Educação) Faculdade de Filosofia e Ciências, Universidade Estadual Paulista, 2011.

FIORINI, Maria Luiza Salzani; MANZINI, Eduardo José. Inclusão de alunos com deficiência na aula de educação física: identificando dificuldades, ações e conteúdos para prover a formação do professor. Revista Brasileira de Educação Especial, Marília, v.20, n.3, p.387-404, 2014. Disponível em: https://doi.org/10.1590/S1413-65382014000300006. Acesso em: 17 jun. 2019.

FRIEND, M. Co-Teaching: A Simple Solution That Isn`t Simple After All. Journal of Curriculum and Instruction (JoCl), v. 2, n. 2, jul. 2008. Disponível em: http://www.joci.ecu.edu/index.php/JoCl/article/view/17/26. Acesso em: 29 jun. 2018.

FRIEND, Marilyan. Welcome to Co-Teaching 2.0._Rev. Teaching Exceptional Children. vol. 49, n. 4, p. 284-293, 2017 Disponível em: http://web-bebscohost.ez31. periodicos.capes.gov.br/ehost/pdfviewer/pdfviewer?vid=1\&sid=875d62cbd537-4914-91ce-63295b98c9fd\%40sessionmgr102. Acesso em: 29 de out. 2018.

GANDIN, Danilo. O planejamento como ferramenta de transformação da prática educativa, 2008. Boletim da AEC-RS, vol. 24, p. 11-20, 2004. Disponível em: www.maxima.art.br/arq_palestras/planejamento_como_ferramenta_(completo).doc.. Acesso em: 15 ago. 2019.

GLAT, Rosana; PLETSCH, Márcia Denise. O papel da Universidade no contexto da política de Educação Inclusiva: reflexões sobre a formação de recursos humanos e a produção de conhecimento. Rev. Educ. Espec., Santa Maria, v. 23, n. 38, p. 345-356, set./dez. 2010. Disponível em: http://cascavel.ufsm.br/revistas/ojs. Acesso em: 12 set. 2017.

GOODWIN, Donna; WATKINSON, Jane. Inclusive physical education from the perspective of students with physical disabilities. Adapted Physical Activity Quarterly, vol.17, n.4, p. 275-293, 2010. 
GRENIER, Michelle. Coteaching in physical education: a strategy for inclusive practice. Adapted Physical Activity Quarterly, vol. 28, n.2, p. 95-112, 2011.

HEREDERO, Eladio Sebastian. A escola inclusiva e estratégias para fazer frente a ela: as adaptações curriculares. Acta Scientiarum Education, Maringá, v. 32, n. 2, p. 193208, jul./dez., 2010. Disponível em:

http://periodicos.uem.br/ojs/index.php/ActaSciEduc/article/viewArticle/9772. Acesso em: 12 set. 2017.

HUTZLER, Yeshayahu.et al. Perspectives of children with disabilities on inclusion and empowerment: supporting and limiting factors. Adapted Physical Activity Quarterly, vol.19, n.3, p.280-299, 2002.

LEHR, Arthur E. The administrative role in collaborative teaching. NASSP Bulletin, Las Vegas, v. 83: n. 611, p. 105-111, dec. 1999.

MARCONI, Marina de Andrade; LAKATOS, Eva Maria. Fundamentos de metodologia científica. 5. ed. São Paulo: Atlas, 2003.

MARTINS, Sueli Terezinha Ferreira. Educação científica e atividade grupal na perspectiva sócio-histórica. Ciência \& Educação, Bauru, v. 8, n. 2, p. 227-235, 2002.

MENEGOLLA, Maximiliano; SANT'ANNA, Ilza Martins. Por que planejar? Como planejar?. 10. ed., Petrópolis: Vozes, 2001.

MENDES, Enicéia Gonçalves.A radicalização do debate sobre inclusão escolar no Brasil. Rev. Brasileira de Educação, Brasil, v. 11, n. 33, p. 387-559, set./dez. 2006. Disponível em: http://www.scielo.br/pdf/rbedu/v11n33/a02v1133.pdf. Acesso em: 17 set. 2017.

MÜLLER, Lenita Santana. Os profissionais do ensino fundamental e a educação inclusiva. Revista Conteúdo, Capivari, v. 1, n. 4, p. 61-71, 2010.

OLIVEIRA, Patrícia Santos; MUNSTER, Mey de Abreu van. A Consultoria Colaborativa como Estratégia para Inclusão de Estudantes com Deficiência na Educação Física Escolar. In: ALVES, Maria Luiza Tanure; FIORINI, Maria Luiza Salzani; JÚNIOR, Rubens Venditti(Org.). Educação Física, Diversidade e Inclusão: debates e práticas possíveis na escola. Curitiba: Editora Appris Ltda., 2019. P. 87-108.

OLIVEIRA, Patrícia Santos; NUNES, João Paulo da Silva; MUNSTER, Mey de Abreu van. Educação Física Escolar e Inclusão: uma revisão sistemática da produção discente na Pós-Graduação brasileira. Práxis Educativa, Ponta Grossa, v. 12, n. 2, p. 570-590, mai./ago, 2017. Disponível em: https://doi.org/10.5212/PraxEduc.v.12i2.0016. Acesso em: 16 set. 2017.

OLIVEIRA, Patrícia Santos. Consultoria Colaborativa como Estratégia para Promover Inclusão Escolar em Aulas de Educação Física. 2019. 182f. Tese (Doutorado em Educação Especial) - Programa de Pós Graduação em Educação Especial, Universidade Federal de São Carlos - UFSCar, São Carlos, 2019. 
http://dx.doi.org/10.5902/1984686X65968

RODRIGUES, David. A educação física perante a educação inclusiva: reflexões conceptuais e metodológicas. Rev. da Educação Física/UEM, Maringá, v. 14, n. 1, p. 67-73, jan/julho 2003. Disponível em:

http://www.rc.unesp.br/ib/efisica/sobama/sobamaorg/EFelnclusaoDavidRodrigues.pdf. Acesso em: 14 de abr. 2019.

SILVA, Cristiane Rocha; GOBBI, Beatriz Christo; SIMÃO, Ana Adalgisa. O uso da análise de conteúdo como uma ferramenta para a pesquisa qualitativa: descrição e aplicação do método. Organ. rurais agroind., Lavras, v. 7, n. 1, p. 70-81, 2005.

SILVA, Francy Kelle Rodrigues; SANTOS, Darllanea Nascimento; FUMES, Neiza de Lourdes Frederico. Os Professores de Educação Física Escolar e o Atendimento Educacional Especializado nas Escolas Públicas. Revista da Sobama, Marília, vol. 15, n. 2, p. 31-36, 2014.

SOARES, Sandra Regina; CUNHA, Maria Isabel da. Formação do professor: à docência universitária em busca de legitimidade. Salvador: EDUFBA, 2010. 134 p. SciELO Books. Disponível em: https://static.scielo.org/scielobooks/cb/pdf/soares-9788523206772.pdf. Acesso em: 17 de set. de 2018.

SOUZA, Flávia Dias; RESENDE, Luís Maurício Martins. Formação inicial de professores para a educação básica em uma universidade tecnológica: trajetórias de reformulação das licenciaturas numa perspectiva colaborativa. Rev. Formação Docente, Belo Horizonte, vol. 11, n. 21, p. 31-40, 2019. Disponível em: http://www.revformacaodocente.com.br. Acesso em: 12 de out. 2020.

STELLA, Claudia; SEQUEIRA, Vania Conselheiro. Inclusão e o cotidiano escolar: a visão dos professores. Cadernos de Pós-Graduação em Distúrbios do Desenvolvimento, São Paulo, v.13, n.2, p. 70-80, 2013.

TEIXEIRA, Amanda Machado; BERGMANN, Mauren Lúcia de Araújo; COPETTI, Jaqueline. Participação de Estudantes com Síndrome de Down nas Aulas de Educação Física. Revista Exitus, Santarém/PA, vol. 9, n 4, p. 319 - 346, out/dez, 2019. Disponível em: https://pdfs.semanticscholar.org/738c/917fab3384e6009e2aba9cf1df80995b12d0.pdf. Acesso em: 03 de nov. 2020.

TRIPP, April; RIZZO, Terry; WEBBERT, Linda. Inclusion in physical education: changing the culture. JOPERD, v. 78, n. 2, p. 32-48, fevereiro 2007.

\section{Notas}

\footnotetext{
${ }^{1}$ Alguns estados norte-americanos dispõem de um profissional com formação básica em EF especializado no atendimento a ECD.

20 instrumento Roteiro de Observação das Aulas de Educação Física - ROA (COSTA, 2015) foi elaborado para um estudo voltado a população com deficiência visual. Para sua utilização no presente estudo foi generalizado para todas as deficiências. Por isso, chamado de ROA (COSTA, 2015) adaptado.
}

${ }^{3}$ Esse roteiro foi elaborado com base no utilizado por Oliveira (2018), porém foi composto pelas pesquisadoras visando os objetivos desse estudo. 
${ }^{4}$ Brown, Howerter e Morgan (2013) sugerem listas de checagem e preenchimento de formulários para a aplicação de cada etapa do coensino. Mas como são voltados para o contexto escolar norte americano e de sala de aula, muitos itens não condizem com o contexto das aulas de Educação Física e da cultura escolar brasileira. Por isso essas listas de checagem e formulários foram utilizadas para embasar a elaboração do checklist.

${ }^{5}$ A comunicação (primeiro procedimento para a implementação do coensino com base em Brown, Howerter e Morgan (2013)) ocorreu entre os envolvidos no processo por meio de uma reunião individual com cada professor e a PP. Ressalta-se que a comunicação não faz parte da aplicação do coensino.

${ }^{6}$ Os professores participantes da pesquisa cumpriam dois HTPIs por semana. Um desses horários era utilizado quinzenalmente para o coplanejamento.

${ }^{7}$ A atividade Queimada é um jogo coletivo pré-desportivo na qual os participantes são divididos em duas equipes. Sendo uma de cada lado da quadra e não podem invadir o espaço do outro. Utiliza-se uma bola e o objetivo do jogo é acertá-la em um participante do time adversário. Quando se acerta, o adversário é queimado e vai para uma região fora da linha da quadra atrás da equipe adversária e continua sua participação tentando acertar os participantes do time adversário. Vence quem eliminar todos os participantes da equipe adversária primeiro. 